\title{
PENGENALAN ALAT-ALAT PRAKTIKUM FISIKA PADA MATERI OPTIK BAGI SISWA SMA NEGERI 8 MUARO JAMBI
}

\author{
S Purwaningsih ${ }^{1)}$, Nehru $^{1)}$, Jufrida $^{1)}$, H Pathoni ${ }^{1)}$, L Muliawati²) $^{2}$ \\ 1)Program Studi Pendidika Fisika, FKIP, Universitas Jambi, Jambi, Jambi, Indonesia \\ 2)Jurusan Tadris Fisika, Fakultas IImu Tarbiyah dan Keguruan, UIN Sulthan Thaha Saefudin Jambi, Jambi, Jambi, Indonesia \\ Corresponding author :H Pathoni \\ E-mail :haerul_pathoni@unja.ac.id
}

Diterima 10 September 2020, Direvisi 14 November 2020, Disetujui 14 November 2020

\begin{abstract}
ABSTRAK
Berdasarkan observasi yang telah dilakukan di SMA Negeri 8 Muaro Jambi, banyak materi Fisika yang semestinya diajarkan melalui praktikum dan percobaan, karena berbagai faktor maka praktikum dan percobaan fisika sering tidak dilakukan, kendala yang paling banyak dijumpai adanya keterbatasan alat-alat praktikum yang tersedia. Kendala tersebut tentunya tidak dapat dibiarkan, harus dicari penyelesainnya agar pembelajaran fisika dapat berjalan sesuai dengan indikatornya. Demikian pula pada saat pembelajaran alat-alat optik, selama ini hanya dipelajari secara teori saja, pada hal untuk memahami konsep yang baik, disamping mempelajari teori juga harus disertai dengan praktikum agar dapat memahami konsep dengan baik dan juga menambah minat belajar siswa. Di SMA Negeri 8 Muaro Jambi tidak selalu praktikum dapat dilakukan, hal ini terkendala oleh ketiadaan alat-alat yang tersedia, terutama praktikum alat-alat optik. Untuk mengatasi masalah itu perlu dilakukan pengenalan alat-alat optik dan pada akhirnya melakukan praktikumnya agar supaya siswa dapat membuktikan kebenaran teori-teori yang sudah dipelajari. Berdasarkan kegiatan pengabdian kepada masyarakat yang telah dilaksanakan dapat disimpulkan bahwa kegiatan pengabdian sangat dibutuhkan bagi pihak sekolah terutama SMA Negeri 8 Muaro Jambi. Adanya kegiatan pengabdian ini guru fisika merasa terbantu dalam membelajarkan siswa-siswi dan mendapat inspirasi bagi guru untuk melakukan praktikum alatalat optik..
\end{abstract}

Kata Kunci: praktikum alat-alat optik; SMA Negeri 8 Muaro Jambi.

\begin{abstract}
Based on observations in SMA 8 Negeri Muaro Jambi, many Physics topic should be taught with practicum and experiment in laboratory. Many various factors the practicum and physics experiment was not done. The most common obstacle was the lack of practicum tools available. These obstacles certainly can not be tolerated, solutions must be sought so that the learning of physics can proceed according to the indicators. Similarly, when learning optikal devices, so far only studied in theory only, in terms of understanding good concepts, besides studying theory must also be accompanied by a practicum in order to understand the concept well and also increased the student interest in learning. In SMANegeri 8 Muaro Jambi not always practicum can be done, It was constrained by the lack of available equipment, especially practicum of optikal devices. To overcome this problem, it was necessary to introduce optikal devices and ultimately done the practicum. The students could prove the truth of the theories that they have learned. Based on community service activities that have been done, it can be concluded that community service activities were needed for schools, especially SMA Negeri 8 Muaro Jambi. Community service activity feel helped physics teachers in teaching students and got inspiration for teachers to doing the practicum tools optiks.
\end{abstract}

Keywords: optikal equipment practicum; SMA Negeri 8 Muaro Jambi.

\section{PENDAHULUAN}

Tujuan pendidikan nasional adalah membentuk manusia indonesia seutuhnya sehat jasmani rohani,memiliki pengetahuan dan keterampilan, dapat mengembangkan kreativitas dan bertanggungjawab, mampu mengambangkan kecerdasan yang tinggi dan disertai budi pekerti yang luhur. Mengingat tujuan pendidikan tersebut, maka sudah selayaknya pemerintah memperhatikan mutu pendidikan. Mutu pendidikan tidak terlepas dari proses penyelenggaraan pendidikan yang terkait dengan sarana dan prasarana yang tersedia. Salah satu yang dapat menentukan mutu pendidikan adalah ketersediaan sarana yang memadai di Sekolah. Diantaranya adalah ketersediaan Laboratorium disuatu Sekolah. 
Laboratorium merupakan tempat mempraktekkan teori-teori yang dipelajari di dalam Kelas. Demikian pula Laboratorium fisika, merupakan suatu wadah mengembangkan pengetahuan seperti konsep, teori, dan hukum fisika yang sudah dipelajari di dalam Kelas yang pada akhirnya akan mencapai tujuan peran belajar fisika agar dapat memberikan bekal pengetahuan, menanamkan sikap ilmiah kepada sisiwa dan merupakan suatu usaha manusia menggungkapkan rahasia alam.

Dalam pembelajaran fisika, selama ini jarang sekali dilengkapi dengan praktikum atau percobaan di Laboratorium, karena berbagai faktor yang tidak mendukung. Padahal, praktikum sangat berperan bagi pengembangan produk dan proses pembelajaran fisika. Tanpa praktikum, pembelajaran fisika tidak mencapai indikator.

Berdasarkan observasi yang telah dilakukan di SMA Negeri 8 Muaro Jambi, banyak materi Fisika yang semestinya diajarkan melalui praktikum dan percobaan, karena berbagai faktor maka praktikum dan percobaan fisika sering tidak dilakukan, kendala yang paling banyak dijumpai adanya keterbatasan alat-alat praktikum yang tersedia. Kendala tersebut tentunya tidak dapat dibiarkan, harus dicari penyelesainnya agar pembelajaran fisika dapat berjalan sesuai dengan indikatornya.

Demikian pula pada saat pembelajaran alat-alat optik, selama ini hanya dipelajari secara teori saja, pada hal untuk memahami konsep yang baik, disamping mempelajari teori juga harus disertai dengan praktikum agar dapat memahami konsep dengan baik dan juga menambah minat belajar siswa. Di SMA Negeri 8 Muaro Jambi tidak selalu praktikum dapat dilakukan, hal ini terkendala oleh ketiadaan alat-alat yang tersedia, terutama praktikum alatalat optik. Untuk mengatasi masalah itu perlu dilakukan pengenalan alat-alat optik dan pada akhirnya melakukan praktikumnya agar supaya siswa dapat membuktikan kebenaran teori-teori yang sudah dipelajari.

Berdasarkan latar belakang di atas dapat dirumuskan permasalahan yaitu : bagaimana mengenalkan peralatan dan beberapa praktikum pada materi optik pada siswa SMA Negeri 8 Muaro jambi.

\section{METODE}

Metode pelaksaanan yang digunakan dalam kegiatan ini adalan metode penyuluhan, diskusi dan praktek yang disampaikan oleh tim Pengabdian kepada siswa-siswi Kelas X MIA U SMA Negeri 8 Muaro Jambi. Kegiatan pengabdian ini dilaksanakan pada hari Sabtu dan Senin tanggal 6 dan 8 September 2014. Kegiatan ini dilaksanakan dalam beberapa tahap yakni :

\section{Tahap Persiapan}

Tahap pertama yakni tahap persiapan yang dilakukan untuk melaksanakan program ini meliputi melaksanakan survei lokasi tempat pelaksanaan kegiatan, pembuatan proposal dan menyelesaikan administrasi perizinan pada instansi yang akan dilibatkan pada pelaksanaan kegiatan, dan persiapan perlengkapan kegiatan pelatihan (Alat dan bahan pelatihan berupa Kit Optik)

\section{Tahap Pelaksanaan}

Tahap yang kedua adalah Tahap pelaksanaan kegiatan yakni pelaksanaan kegiatan ini dilakukan dua hari, yaitu hari Sabtu tanggal 6 September 2014 jam 09.00-12.00 WIB, yang meliputi registrasi peserta oleh siswa-siswi kelas X MIA, pembukaan, kegiatan pelatihan ini dibuka oleh ketua pelaksanaan pengabdian diikuti oleh Kepala SMA Negeri 8 Muaro Jambi, siswa dibagi dalam beberapa kelompok dan masing-masing kelompok bergiliran mendapatkan penjelasan mengenai alat-alat praktikum untuk materi optika dan kegiatan praktikum optika.

Sedangkan pelaksanaan pada hari kedua yaitu Senin tanggal 8 September 2014 jam 09.00-11.30 WIB meliputi melaksanakan Praktikum yaitu pengambilan data dilakukan berkelompok, masing -masing kelompok terdiri dari 3 orang. Praktikum ini dilaksanakan lima percobaan.

Percobaan 1. Memberikan penjelasan mengenai pemantulan yang terjadi pada cermin datar serta menjelaskan alat yang diperlukan untuk percobaan tersebut serta melakukan percobaaan dan mengambil data serta membuktikan hasil percobaan tersebut dengan teori yang ada.

Percobaan 2. Memberikan penjelasan mengenai pemantulan pada cekung, bagaimana sifat bayangan yang dihasikan serta menjelaskan alat yang diperlukan untuk percobaan tersebut serta melakukan percobaaan dan mengambil data serta membuktikan hasil percobaan tersebut dengan teori yang ada.

Percobaan 3. Memberikan penjelasan mengenai pembiasan yang terjadi pada kaca planparalel serta menjelaskan alat yang diperlukan untuk percobaan tersebut serta melakukan percobaaan dan mengambil data serta membuktikan hasil percobaan tersebut dengan teori yang ada.

Percobaan 4. Memberikan penjelasan mengenai pembiasan yang terjadi pada prisma 
serta menjelaskan alat yang diperlukan untuk percobaan tersebut serta melakukan percobaaan dan mengambil data serta membuktikan hasil percobaan tersebut dengan teori yang ada.

Percobaan 5. Memberikan penjelasan mengenai pembiasan yang terjadi pada lensa, bagaimana sifat bayangan yang dihasilkan serta menjelaskan alat yang diperlukan untuk percobaan tersebut serta melakukan percobaaan dan mengambil data serta membuktikan hasil percobaan tersebut dengan teori yang ada.

Tahap terakhir adalah mendiskusikan hasil praktikum yang sudah dilakukan dan menjawab pertanyaan yang ada dipenuntun praktikum.

\section{HASIL DAN PEMBAHASAN}

Berdasarkan hasil pengamatan selama pengabdian berlangsung diperoleh bahwa, Guru bidang studi fisika dan Kepala sekolah sangat senang dengan adanya kegiatan pengabdian ini mereka merasa dapat memberi inspirasi bagi sekolah yang pada mulanya para guru bidang studi fisika menyampaikan materi alat-alat optik hanya secara teori saja dengan adanya pelatihan praktikum ini dapat membantu guru fisika membekali siswasiswinya untuk memahapi konsep alat-alat optik.

Dari gambar 1 terlihat bahwa siswa sangat antusias melakukan percobaan kaca plan parallel. Mereka sangat merespon positifterhadap kegiatan pengabdian ini, terlihat dari keseriusan siswa dalam memperhatikan penjelasan praktikum dan demikian pula dalam pelaksanaan praktikum siswa-siswi termotivasi dalam mencobakan alat-alat optik serta pengambilan data, karena selama ini tidak pernah dijumpai dalam belajar optika.

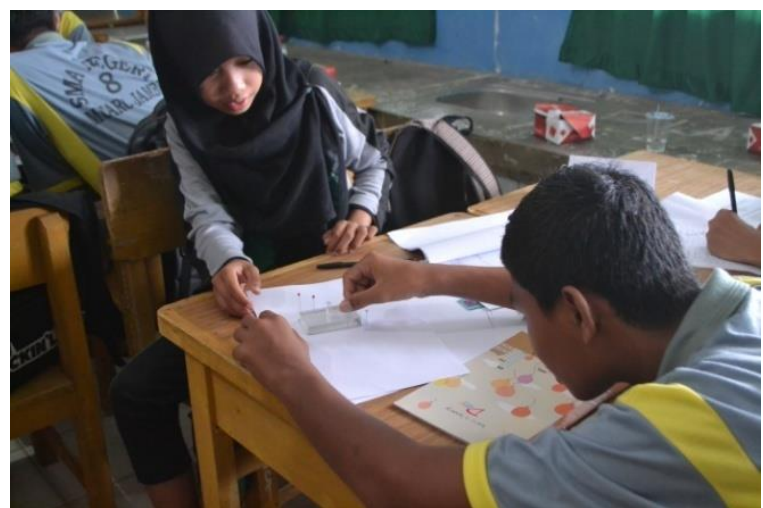

Gambar 1. Siswa-siswi SMAN 8 Muaro Jambi sedang melaksanakan percobaan kaca plan paralel.
Pada Gambar 2 dapat dilihat juga bahwa tim pengabdian sangat antusias dalam memberikan penjelasan kepada siswa.

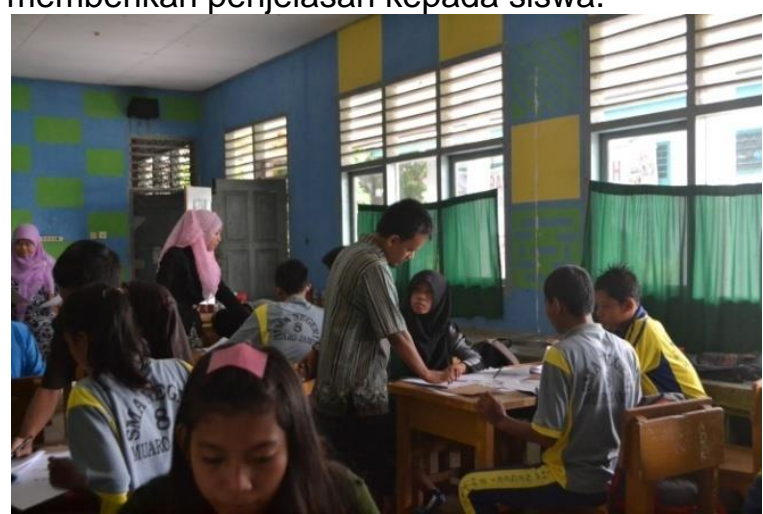

Gambar 2.Tim Pengabdian sedang membagikan materi praktikum kepada siswasiswi SMA N 8 Muaro Jambi.

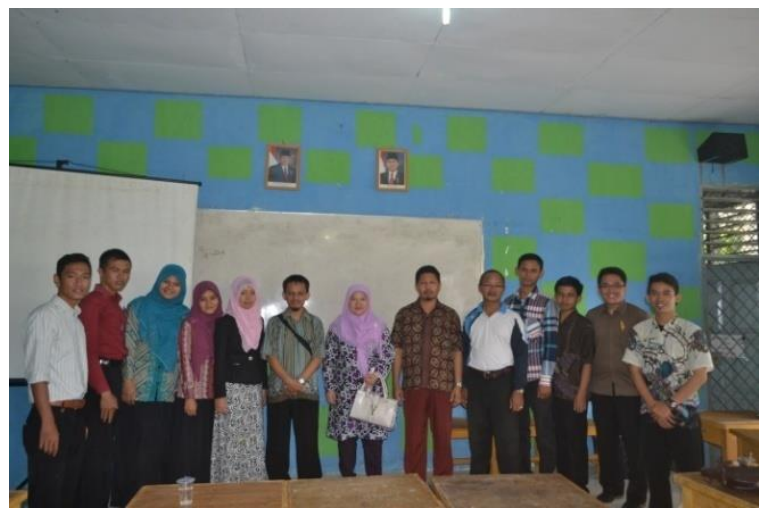

Gambar 3. Foto bersama antara tim pengabdian, mahasiswa Pendidikan Fisika, dan Para guru SMA N 8 Muaro Jambi

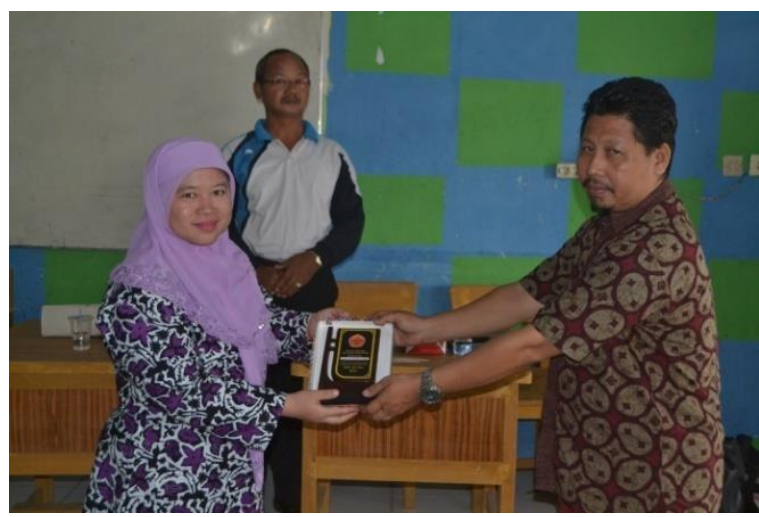

Gambar 4. Pemberian Ucapan terima kasih dan kenang-kengan berupa Plakat dari Tim pengabdian kepada pihak sekolah SMA N 8 Muaro Jambi

Pada akhir kegiatan guru, tim pengabdian dan siswa melakukan foto bersama dan pemberian kenang-kenangan dari ketua tim pengabdian kepada pihak sekolah yang diwakili oleh wakil kepala sekolah bidang kurikulum. Selain itu ,kegiatan ini ditutup oleh ketua 
pelaksanaan pengabdian dan wakil kepala sekolah seperti terlihat pada gambar 3 dan 4 .

\section{SIMPULAN DAN SARAN \\ Simpulan}

Berdasarkan kegiatan pengabdian kepada masyarakat yang telah dilaksanakan dapat disimpulkan bahwa kegiatan pengabdian sangat dibutuhkan bagi pihak sekolah terutama SMA Negeri 8 Muaro Jambi, dengan adanya kegiatan pengabdian ini guru fisika merasa terbantu dalam membelajarkan siswa-siswi dan mendapat inspirasi bagi guru untuk melakukan praktikum alat-alat optik. Setelah melakukan kegiatan pelatihan praktikum alat-alat optik, Siswa-siswi kelas X MIA U sudah terlatih dalam melakukan praktikum dan pengambilan data serta pengolahan data. Selain itu, perlu adanya pembelajaran yang kreatif dan inovatif terhadap siswa salah satunya dengan melakukan praktikum alat-alat optika.

\section{Saran}

Pihak sekolah menyambut positif kegiatan pengabdian ini, disarankan pengabdian berikut nya dapat dilakukan kembali di SMA Negeri 8 Muaro Jambi untuk praktikum pada materi yang lainnya.

\section{DAFTAR RUJUKAN}

Abdullah, M. (2006). Diktat Kuliah Fisika Dasar II Tahap Persiapan bersama ITB. ITB Press.

Halliday, \& Resnick. (2015). Fundamental of Physics 10th Edition. In Wiley.

Tim Fisika Dasar II. (2006). Penuntun Praktikum Fisika Dasar II. FKIP Universitas Jambi.

Mulyasa. (2005). Menjadi Guru Profesional. PT Remaja Rosdakarya.

Sadiman, A. S. (1990). Media Pendidikan. Rajawali.

Sheal, P. (1989). How to Develop and Present Staff training Courses. Kogain Page Ltd.

Slameto. (2003). Belajar dan Faktor-faktor yang Mempengaruhinya. Rineka Cipta.

Tipler, P. A. (1998). Fisika Untuk Sains dan Teknik. Jakarta: Erlangga.

Yamin, M. (2007). Strategi pembelajaran berbasis kompetensi. GP Press.

Zemansky, S. dan. (1994). Fisika Untuk Universitas 2 Listrik dan Magnet. Binacipta. 